\title{
Perspectivas de Usuários em Sofrimento Psíquico
}

\section{Sobre um Serviço de Pronto Atendimento}

\author{
Beatriz da Silva Souza ${ }^{1}$ \\ Danielle Abdel Massih Pio ${ }^{1}$ \\ ${ }^{1}$ Faculdade de Medicina de Marília, Marília, SP, Brasil. \\ ${ }^{1}$ Faculdade de Medicina de Marília, Marília, SP, Brasil. \\ Gabriela Teixeira Ribeiro de Oliveira ${ }^{1}$ \\ ${ }^{1}$ Faculdade de Medicina de Marília, Marília, SP, Brasil.
}

\begin{abstract}
Resumo: Este trabalho analisou a perspectiva dos usuários sobre o atendimento à demanda de sofrimento psíquico em um serviço pré-hospitalar, a fim de identificar sua percepção acerca da assistência e do acolhimento de sua queixa, quais recursos são oferecidos diante de suas necessidades e a resolutividade do cuidado direcionado à saúde mental, quanto à articulação da rede de atenção psicossocial e da rede de urgência e emergência. Constituiu-se em um estudo qualitativo, de caráter descritivo-exploratório, que utilizou como instrumento entrevista semiestruturada composta por nove questões que abrangem os principais temas relacionados ao estudo. A amostra não-probabilística intencional foi composta por 20 usuários. A metodologia contemplou a análise temática, por meio da técnica de análise de conteúdo, segundo Bardin (2011), e adotou como referencial teórico a psicanálise. Foi possível categorizar os resultados obtidos em três temas: a) Percepção dos usuários quanto às queixas e aos prejuízos; b) Demanda, acesso e vínculo; e c) Atendimento e resolubilidade. Verificou-se as queixas mais frequentes relacionadas aos sintomas gerais, que podem ser considerados de base somática, e os prejuízos considerados graves. Os dispositivos reconhecidos como potentes nesse processo foram o vínculo, ainda que de caráter transitório, e o acesso, ambos fatores determinantes para a procura do serviço pelos usuários entrevistados. Porém, o acolhimento, que possui relação direta com a percepção de resolubilidade, pode ser mais desenvolvido, no sentido de qualificação da escuta, da clínica ampliada e da abordagem integral nos cuidados disponibilizados.
\end{abstract}

Palavras-chave: Sofrimento Psíquico, Serviços Pré-hospitalares, Acolhimento, Emergência.

\section{The Perspectives of Users in Psychic Suffering About an Emergency Service}

\begin{abstract}
This study investigated the perceived care to individuals in psychic suffering according to users of a pre-hospital service, considering assistance and complaints handling, the offered resources, and the resoluteness of mental health care as to the articulation of the psychosocial care network and the emergency network. This qualitative descriptive-exploratory study was conducted with data collected by means of a nine-question semi-structured interview conducted with a non-probabilistic sample of 20 users. Data underwent thematic content analysis, according to Bardin (2011), in the light of psychoanalysis. The results were categorized into three themes: 1) users' perception regarding complaints and losses; 2) demand, access, and bonds; and 3) service and resoluteness. The most frequent complaints were related to the general symptoms, considered somatic, resulting in serious damages. The bonds, even though temporary, and access were considered as potent devices in the process, comprising determining factors for the demand of the service. However, the service can improve the
\end{abstract}


handling (directly associated with the perceived resoluteness) regarding listening, extended clinic, and integral approach in the care provided.

Keywords: Psychic Suffering, Pre-hospital Services, User Embracement, Emergencies.

\title{
Perspectivas de Usuarios en Sufrimiento Psíquico Sobre un Servicio de Urgencia
}

\begin{abstract}
Resumen: Este trabajo analizó la perspectiva de usuarios sobre la atención al sufrimiento psíquico en un servicio prehospitalario, específicamente en relación a la asistencia y cómo su queja fue acogida, cuáles son los recursos ofrecidos ante sus necesidades y la resolutividad del cuidado dirigido a la salud mental respecto a la articulación de la red de atención psicosocial y de la de urgencia y emergencia. Este es un estudio cualitativo, de carácter descriptivo-exploratorio, que utilizó como instrumento entrevista semiestructurada compuesta por nueve preguntas sobre los principales temas relacionados al estudio. La muestra no probabilística intencional se compuso de 20 usuarios. La metodología contempló el análisis temático, y la técnica empleada fue el análisis de contenido de Bardin (2011) teniendo como referencial teórico el psicoanálisis. Se categorizó los resultados obtenidos en tres temas: a) Percepción de usuarios sobre quejas y pérdidas; b) Demanda, acceso y vínculo; y c) Atención y resolutividad. Se observaron las quejas más frecuentes relacionadas con síntomas generales, que pueden considerarse de base somática, y los perjuicios considerados graves. Los dispositivos reconocidos como potentes del proceso fueron el vínculo, aunque de carácter transitorio, y el acceso, ambos factores determinantes para la demanda al servicio de los usuarios entrevistados. Pero la acogida que tiene relación directa con la percepción de resolutividad puede ser más desarrollada en el sentido de calificación de la escucha, la clínica ampliada y el abordaje integral en los cuidados disponibles.
\end{abstract}

Palabras clave: Sufrimiento Psíquico, Servicios Prehospitalarios, Acogimiento, Urgencias Médicas.

\section{Introdução}

Nos últimos dez anos, houve um aumento de incidência de transtornos mentais na população mundial. O Brasil apresenta percentual relevante nesse contexto, conforme relatório nacional cujos dados informam que 5,8\% (11.548.577) de brasileiros têm diagnóstico de depressão e 9,3\% (18.657.943), de ansiedade (Nações Unidas no Brasil, 2017). Tal informação revela a necessidade de investigar de que forma o sistema de saúde acolhe essa demanda crescente de saúde mental.

Após a Reforma Psiquiátrica iniciada na segunda metade dos anos 1970 e oficializada com a Lei n. 10.216 de 2001, o tratamento para a saúde mental no país começa a priorizar a desinstitucionalização e a oferecer serviços alternativos às internações em hospitais psiquiátricos. Para tanto, a Rede de Atenção Psicossocial (RAPS), instituída por meio da Portaria n. 3.088 de 2011, objetiva articular ações e serviços de saúde em diferentes níveis de complexidade, tendo em vista a intersetorialidade, a promoção de autonomia e a reabilitação de seus usuários (Portaria n. 3.088, 2011).
A partir da Reforma, os serviços de urgência e emergência passaram a complementar, como parte da RAPS, o atendimento às demandas de pessoas com sofrimento mental. Nas demandas de urgência e emergência, tem-se o risco de morte como principal critério de gravidade, motivo pelo qual os atendimentos são pontuais e têm a intenção de estabilizar o máximo possível o quadro geral do indivíduo, com base na classificação de risco e no prognóstico (Portaria n. 10, 2017). Assim, situam-se em segundo plano outros aspectos dos sujeitos, tais como seu contexto social e a escuta sobre sua percepção acerca dos sintomas (Giglio-Jacquemot, 2005).

Considerando os critérios nos atendimentos às urgências, nem sempre o que é descrito como "agudo, com prioridade de cuidados" tem o mesmo significado para todos os atores sociais envolvidos. A interpretação e tratamento desses sintomas ainda se revestem de um padrão social regido pela medicalização e são voltados ao modelo biomédico, caracterizado pela centralização 
do cuidado no profissional médico e pela fragmentação de terapêuticas curativas e processos de trabalho, modelo ainda hegemônico em saúde mental (Fertonani, Pires, Biff, \& Scherer, 2015).

Assim, há necessidade crescente de alta resolutividade nesses cenários, que novamente remete à mitigação dos sintomas, sem problematização de suas recorrência ou origem. Logo, no contexto apresentado, há pouco investimento em práticas que de fato contemplem as reais demandas dos usuários em sofrimento psíquico.

Para levantamento de produções, foi utilizada a base de dados da Biblioteca Virtual de Saúde (BVS) com as palavras-chave: serviços médicos de emergência e atenção à crise em saúde mental (7 resultados), serviços pré-hospitalares e saúde mental (11 resultados) e acolhimento, emergência e sofrimento psíquico (9 resultados). Como critérios de filtro, aplicou-se a seleção das bases de dados no LILACS e Index Psicologia; porém, devido aos poucos resultados com conteúdos compatíveis com a pesquisa, optou-se por não limitar o intervalo de tempo de publicações e por utilizar diferentes combinações entre os termos de busca. Os critérios empregados para a escolha dos artigos foram as produções que estivessem voltadas à perspectiva do usuário, que discutissem a articulação da rede de saúde entre diferentes níveis de atenção e que analisassem o atendimento das demandas dos sujeitos em sofrimento psíquico.

Como resultados relevantes da pesquisa bibliográfica destacaram-se a baixa resolutividade da Atenção Primária em Saúde (APS), a visão médico-centrada e acolhimento insuficiente, as dificuldades em contemplar as demandas recebidas por meio de assistência e entrevista homogêneas na admissão dos usuários, a complexidade em proporcionar a continuidade do tratamento e a necessidade de articulação intersetorial para atendimento integral (Baratieri, Almeida, Lentsck, \& Natal, 2017; Brito, Bonfada, \& Guimarães, 2015; França, 2005; Macêdo, Pimenta Filho, Sotelo, Belaga, \& Santimaría, 2010). De acordo com Jardim (2014), mantém-se um atendimento não correspondente ao de atenção à pessoa em crise, com abordagem de curta duração, sem instrumentos e estratégias que fundamentem tratamentos longitudinais e que se conectem aos desencadeadores $\mathrm{e}$ contextos do indivíduo.

Houve dificuldade em identificar artigos que relacionassem as variáveis anteriormente descritas, ou seja, que associassem e relacionassem as perspectivas da RAPS aos serviços de urgência. Por isso, foram considerados apenas 9 artigos que apresentavam afinidade, mesmo que indireta, ao tema desta pesquisa.

Entre os resultados bibliográficos, constatou-se a predominância do despreparo das equipes e dos locais de atendimento nessas situações, no acolhimento e em encaminhamentos possíveis, de forma que muitas vezes a demanda não é considerada por eles apesar de também fazer parte da Rede de urgência e emergência, o que marginaliza ainda mais esses usuários por não proporcionar os recursos existentes na rede para seu tratamento.

Nesse sentido, este estudo teve como foco a perspectiva do usuário acerca da assistência prestada e de que forma sua queixa foi acolhida, quais recursos foram oferecidos diante de suas necessidades e qual foi a resolutividade do cuidado direcionado à saúde mental quanto à articulação das Redes de Atenção à Saúde (RAS), tanto psicossocial quanto de urgência e emergência. Parte-se do pressuposto de que a população visualiza o Pronto Atendimento (PA) como meio de alcance a esses recursos, porém, não tem suas demandas atendidas de forma integral, uma vez que ainda falta articulação da rede de atenção e preparo dos profissionais para o cuidado ampliado, especialmente diante das demandas de sofrimento psíquico.

\section{Metodologia}

Trata-se de uma pesquisa qualitativa, com método indutivo e caráter descritivo-exploratório (Minayo,2013). Foram entrevistados 20 usuários do serviço de saúde do PA com queixas relativas direta ou indiretamente a sofrimento psíquico, que constituíram uma amostra não probabilística intencional selecionada segundo os seguintes critérios de inclusão: residentes da cidade do estudo, maiores de 18 anos, que aceitassem participar da pesquisa e que não possuíssem morbidade clínica com prioridade de atendimento e risco no momento da realização da entrevista semiestruturada.

O local de realização da pesquisa foi em um município de médio porte do interior paulista, em um serviço de PA que compõe a oferta de serviços pré-hospitalares, correspondente ao nível intermediário de atenção e componente da Rede de Urgência e Emergência (RUE) da cidade. O município possui 36 unidades de Estratégias de Saúde da Família (ESF) e 12 unidades de Unidades Básicas de Saúde (UBS). Como referência aos atendimentos em urgência psiquiátrica adulto e infantil 24 horas, há o ProntoSocorro em Saúde Mental que integra o atendimento 
de alta complexidade de um serviço hospitalar (referência para 62 munícipios), com acesso condicionado por encaminhamento médico, sobretudo pelo serviço do SAMU, responsável pela regulação em urgência e emergência do município.

$\mathrm{O}$ instrumento de pesquisa foi composto pela caracterização de dados sociodemográficos dos participantes (idade, sexo, bairro, profissão/ocupação, nível de escolaridade e estado civil), seguido de questões que direcionassem a apreensão dos dados necessários para alcançar os objetivos propostos. Dessa forma, foram elaboradas nove questões em um roteiro semiestruturado que abrangessem os principais temas relacionados ao estudo: frequência de procura ao serviço; procura anterior a algum outro local de saúde; principal motivo relatado para a busca de atendimento; queixas referidas durante $o$ atendimento; de que forma o usuário considerou o acolhimento a sua demanda; encaminhamentos realizados; nível de gravidade e percepção dos prejuízos; e, por fim, a resolutividade do sistema de saúde para a demanda apresentada.

Neste estudo, considerou-se o sofrimento psíquico como um conceito amplo, relativo a uma experiência subjetiva, que pudesse abranger também os prejuízos no cotidiano de quem os vivencia, e atrelado à angústia e ao sentimento de desamparo (Pinheiro, Aguiar, \& Mendes, 2008). Foi ponderado o reconhecimento desse sofrimento pelos próprios participantes como determinante para realização da entrevista, assim como a identificação, por parte dos trabalhadores do serviço que ofereceram o atendimento psicológico, daqueles que qualificaram como necessitados de uma escuta.

A coleta de dados foi realizada por duas residentes de psicologia do programa de Residência Integrada Multiprofissional em Urgência no período de dois meses (outubro e novembro de 2018), com abrangência de todos os dias da semana e alguns sábados. O estudo foi iniciado após aprovação do Comitê de Ética em Pesquisa (CEP) sob o parecer de $n^{\circ} 2.886 .388$, de acordo com as atribuições definidas na Resolução CNS 466/2012 e na Norma Operacional no 001/2013. Os participantes tiveram respeitadas as condições do Termo de Consentimento Livre e Esclarecido (TCLE) apresentado durante acolhimento, e as entrevistas foram realizadas e gravadas em local reservado após o aceite do participante, com duração aproximada de meia hora.

A análise descritiva contempla caracterização das frequências de resposta e percentuais do perfil socioeconômico, seguidos de análise temática. A técnica empregada, a análise de conteúdo, busca a compreensão dos dados obtidos e, se possível, indicadores que permitam maior conhecimento a partir das variáveis estudadas (Bardin, 2011). Como referencial teórico será utilizada a psicanálise, com ênfase na subjetividade dos sujeitos envolvidos na interpretação do material colhido.

\section{Resultados e discussão}

\section{Análise descritiva}

Da amostra total (20), obteve-se 9 usuários que referiram queixas diretamente associadas ao sofrimento psíquico e 11 com sintomas indiretos. Quanto à abordagem dos acolhimentos, 14 abordados foram interpelados após atendimento clínico e conduta médica; 3 foram encaminhados por equipe de enfermagem logo após a classificação de risco devido à identificação de queixa diretamente relacionada ao sofrimento psíquico; e 3 procuraram pelo serviço por interesse direto pelo atendimento psicológico. Em relação aos participantes da pesquisa, obteve-se como resultado o seguinte perfil sociodemográfico com referência no total de 20 participantes e nos dados mais recorrentes:

\section{Tabela 1}

Perfil sociodemográfico predominante dos participantes.

\begin{tabular}{|c|c|c|c|c|c|c|}
\hline & Sexo & Idade & Escolaridade & Profissão/ ocupação & Estado civil & Bairro \\
\hline & Feminino & $\begin{array}{c}40 \mathrm{a} \\
70 \text { anos }\end{array}$ & $\begin{array}{c}\text { Ensino } \\
\text { Fundamental incompleto }\end{array}$ & $\begin{array}{c}\text { Aposentada/ } \\
\text { pensionista/do lar }\end{array}$ & Casada/amasiada & $\begin{array}{l}\text { Mesma região/ } \\
\text { Região próxima }\end{array}$ \\
\hline Total & 15 & 14 & 8 & 9 & 12 & 14 \\
\hline
\end{tabular}




\section{Análise temática}

Com base na análise de conteúdo das entrevistas e aproximações entre os núcleos de sentido encontrados, foi possível categorizar os resultados obtidos nos seguintes temas: a) Percepção dos usuários quanto às queixas e aos prejuízos; b) Demanda, acesso e vínculo; e c) Atendimento e resolubilidade. Os participantes da pesquisa serão representados com nomes fictícios a fim de preservar a privacidade na identificação das falas, sem prejuízo do anonimato.

\section{Tema 1: Percepção dos usuários quanto}

às queixas e aos prejuízos

Nos serviços de urgência, utiliza-se como método a classificação de risco, uma ferramenta que dá subsídio ao parecer clínico e visa a identificação da gravidade do caso e atendimento em tempo apropriado para a segurança do usuário (Portaria n. 10, 2017). Os usuários iniciam seu percurso no local expressando sua queixa, que seria uma síntese de sinais incômodos ou desconfortáveis predominantes no momento, ditos de forma manifesta (Almeida, 2005).

Verificou-se que as queixas referidas inicialmente como sintomas somáticos, "dor, tremores, tontura, náusea, etc.”, vinham acompanhados ou não de sinalização de uma demanda, ou seja, o que estaria latente na procura pelo serviço e exigiria um acolhimento mais detalhado e uma escuta ampliada e qualificada para ser reconhecida, quando correlatada a eventos estressores recentes e a solicitação do contato com a psicologia (Almeida, 2005).

O sofrimento psíquico apresentou-se de formas variadas, dentre elas, como sintoma físico, influenciado pelo contexto em que a pesquisa foi realizada, um serviço de média complexidade que requer um cuidado centrado na dimensão biológica. Fortes, Tófoli e Baptista (2010) apontam como características dos serviços de saúde aos quais pacientes que somatizam costumam recorrer: condutas centradas no adoecimento físico; ausência de outros recursos para lidar com queixas sem evidências clínicas; diálogo com equipe sem abranger área psicossocial; e rede de saúde pouco articulada, de maneira prejudicial ao vínculo.

Percebe-se, desse modo, o quanto a abordagem da equipe durante o atendimento e a percepção do usuário sobre sua queixa são influenciados por uma visão integral ou fragmentada do cuidado. No Dicionário da Educação Profissional em Saúde, Pinheiro (2008) problematiza os diferentes sentidos da palavra "integralidade".
Quando relacionada a uma prática cotidiana construída a partir do encontro da equipe com o usuário, seria uma escuta para além do biológico e objetivo, que leve em conta também os modos de prevenir e o uso de recursos para identificar a real necessidade de saúde, que está associada dialeticamente com os aspectos sócio-históricos dos usuários, não somente da doença.

Segundo Perrusi (2015), o modo de vida contemporâneo oportunizou uma intolerância ao sofrimento psíquico, sobretudo devido à valorização do bem-estar, que fortalece meios imediatos e superficiais de enfrentamento, tais como a recorrência do uso de psicofármacos. Nesse sentido, duas participantes evidenciam em suas falas que a procura pelo serviço estava diretamente ligada ao uso dessas medicações: ". . . por ser um atendimento rápido que me tira a dor" (P. Ferreira); e "Porque é perto da minha casa, e eles têm os remédios pra dar que já dá uma aliviada, você volta pra casa sem dor" (M. Cardoso).

Tal concepção é análoga à dificuldade por parte de alguns entrevistados em aproximar as diferentes dimensões de ser humano, de forma que eles necessitam encontrar subsídios para permanecer com a compreensão de uma dicotomia entre o corpo e a mente, segundo a qual um problema de saúde estaria vinculado a um aspecto em detrimento do outro. Os aspectos físicos, isto é, o desconforto ou incômodo, seriam passíveis de eliminação por meio do remédio, ainda que de forma momentânea (Perrusi, 2015).

O reconhecimento dos prejuízos por parte dos entrevistados demonstra a extensão do impacto da vivência de tais problemas nas relações interpessoais, em sua funcionalidade e na perda de qualidade de vida. Gonçalves e Kapczinski (2008) debatem sobre os impactos dos transtornos mentais na vida dos usuários e nos serviços de saúde utilizados, e apontam resultados significativos quanto ao aumento de procura pelos serviços de emergência no mesmo ano, assim como ao agravo de outros problemas de saúde devido à baixa adesão aos demais tratamentos de saúde.

Logo, é necessário atentar para as comorbidades clínicas principalmente de doenças crônicas, por tratar-se de população predominantemente com idade de transição da fase adulta para a idosa. Estudos apontam que o sofrimento psíquico influencia em diversos fatores como adesão aos tratamentos, prognóstico ou fatores de risco (Ministério da Saúde [MS], 2013). De maneira semelhante, o entrevistado E. Pereira relata que as consequências do sofrimento psíquico em seu cotidiano o atrapalham de forma relevante: 
Ah uns 90\% porque eu tinha uma vida normal diária assim, saía, conversava bastante com meus amigos ia na casa dos familiares mesmo, hoje não sinto nem vontade mais por causa desses sintomas, só fico em casa mesmo deitado assistindo à televisão e converso com os pais. A vontade mesmo porque não é tanta, desanima né, a saúde eu não me sinto bem pra querer ficar saindo. Financeiro também porque desempregado, as coisas vão piorando, emocional também. Por mim, por exemplo, que eu sou novo eu não queria tomar medicamento nenhum nem de pressão, eu queria ter uma rotina normal igual eu tinha antes, praticar meus esportes tá 100\% minha saúde, só que aí depois começou a acontecer esses problemas née aí minha rotina mudou.

Os disparadores mais citados para a procura de atendimento na pesquisa foram as situações deluto ou separação recente, não necessariamente agudas; conflitos familiares com episódios de violência, enquanto testemunha e/ou vítima; e crises de ansiedade, algumas em comorbidade com cardiopatias. De forma secundária, a demanda em decorrência de dependência química ou de álcool, tanto por parte dos usuários quanto por familiares, também se mostrou significativa. Assim, é importante salientar também o caráter social de tais demandas, pois os vínculos fragilizados tanto no âmbito familiar quanto em demais contextos de convívio referente às instituições, contribuem para um processo de exclusão e refletem as dificuldades vivenciadas (Barreto, 2017; Giglio-Jacquemot, 2005).

Observou-se correlação dos disparadores encontrados na pesquisa com o conceito de Determinantes Sociais em Saúde (DSS), que define as iniquidades que se originam nas relações de dominação e exploração e de divisão injusta de poder. Dentre os fatores citados, Buss e Pellegrini (2007) discutem a importância dos vínculos nas relações, por meio dos quais a coesão social tem influência direta sobre a formação de redes solidárias e configura um fator de proteção no estilo e qualidade de vida.

Sobre a demanda que abordou o sofrimento psíquico de maneira declarada, encontraram-se usuários com diversas características, tais como: histórico de acompanhamentos anteriores com psiquiatras ou psicólogos; em tratamento com medicação contínua; com alterações afetivas e volitivas consideráveis; e que não haviam encontrado outro lugar na rede de saúde que acolhesse ou trabalhasse tais questões. Isto é, há usuários da rede de saúde mental com um conhecimento mais amplo sobre o tema, que se mobilizam também pelas causas dos problemas e não somente pelas consequências. Esses entrevistados mostraram-se conscientes da importância de expressar a angústia e tentar encontrar um significado para as experiências de adaptação ou desafiadoras pelas quais estavam passando ou já haviam passado, além de possuírem uma percepção mais alinhada à realidade vivenciada e suas relações.

Essa angústia, esse medo, tentando buscar uma ajuda, alguma coisa que me devolva um pouco de paz, alguma coisa que me leve a agir se eu tô agindo certo com a minha família, comigo, porque eu preciso estar bem pra cuidar, por ter uma criança especial que tem um autismo, uma situação toda misturada e ter que dar conta de tudo isso e da casa, de limpeza, é parece mais um desespero de estar buscando alguma coisa que me ajude em tudo (P. Ferreira).

A partir disso, percebe-se que a oferta dos serviços na RAPS ainda encontra desafios para a consolidação de um modelo de cuidado em saúde mental territorializado e uma produção de cuidados mais resolutivos e promotores de autonomia, visto que a desarticulação com as demais redes que compõem os serviços de saúde, a predominância da terapêutica medicamentosa, a manutenção de atendimentos clínicos individualizados e, portanto, os vínculos fragilizados desse cenário, são apontados como os principais causadores da dificuldade na adesão aos tratamentos oferecidos e da ausência de alinhamento das expectativas dos usuários com os tratamentos disponíveis (Nunes, Guimarães, \& Sampaio, 2016).

As autoras Jardim e Dimenstein (2007) chamam a atenção para o atendimento dos usuários com demanda relativa à saúde mental nos serviços de urgência e problematizam o fato de tratar-se também de analisadores da rede de saúde mental como um todo, principalmente devido aos obstáculos que os profissionais encontram, tais como as experiências desorganizadoras diante do encontro com o sofrimento psíquico e a falta de qualificação, até mesmo nos serviços especializados nesse tipo de demanda.

Outrossim, as autoras ressaltam ainda o caráter "paliativo" do reducionismo aos sintomas e da 
desresponsabilização dos usuários, que consequentemente tornam-se propagadores desse processo alienante de "cuidado" com a saúde mental. Como proposta, indicam uma mudança de paradigma de "urgência psiquiátrica" para "atenção urgente à pessoa em crise".

\section{Tema 2: Demanda, acesso e vínculo}

De acordo com as respostas ao instrumento, apreende-se que a proposta de funcionamento de cuidado em saúde de porta aberta complementar à Atenção Básica influenciou de maneira positiva a acessibilidade ao serviço, pois trata-se de uma assistência voltada para a urgência com funcionamento 24 horas.

Dentre os participantes, 7 pessoas apontaram que constituem população adstrita ao território próximo, o que incrementa a procura pelo local devido à localização e facilidade no deslocamento; porém, o fator predominante citado pelos usuários (10 participantes) para a escolha pelo serviço foi a preocupação com os sintomas: "Pela gravidade dos sintomas porque eu tava tremendo, eu venho correndo pra cá porque é pertinho de casa né?" (A. Silva); e "Primeiro que como eu falei eu sinto esses negócios ruim, minha pressão sobe, fico com aquele batimento parece que a gente vai morrer. Por isso que eu venho" (J. Fernandes).

A urgência relaciona-se igualmente à interpretação da necessidade de um atendimento, mesmo que não seja por risco de morte. Além disso, como já discutido anteriormente, no sintoma estão implícitas diversas outras condições que podem ser inadiáveis no contexto do usuário. O que se vê muitas vezes são os relatos de queixas que já ocorrem há vários dias, por exemplo, o que na perspectiva dos usuários pode ser tão prejudicial quanto um quadro agudo, visto que afeta diretamente a funcionalidade nas relações e na produtividade em seu cotidiano (Giglio-Jacquemot, 2005).

Outra possibilidade seria a "urgência" ser vista segundo a lógica imediatista, também relacionada à baixa tolerância a frustrações, à ansiedade ou ao modo de sentir a angústia, que se exemplifica na fala da participante: "Hoje eu vim direto pra cá, quando eu tenho tempo de ir com antecedência eu vou lá (unidade de referência), mas quando não tenho tempo eu venho aqui, quando tem que ser rápido eu venho aqui, não pode esperar né?" (D. Santos).

Ao se referir a outro local em "eu vou lá", a entrevistada trata de sua unidade de saúde de referência; no decorrer do processo de coleta, foi explorada também a relação com as UBS/ESF, pois notou-se importante influência dessa variável na facilitação do vínculo com o serviço. O usuário C. Oliveira evidencia questões como o entendimento de que o PA seria uma alternativa às UBS/ESF ou que estas seriam utilizadas de forma substitutiva. Nesses cenários, especialmente no das UBS devido ao território mais abrangente, o acolhimento disponibilizado não seria suficiente para todos: “. . eu vim direto pra cá, porque meu posto não tem ninguém, tem uma quantidade de paciente pra atender, acabou, acabou. Como é bastante gente, por isso que eu não fui lá..." (C. Oliveira).

C. Oliveira refere-se à diferença entre a demanda e a oferta das unidades de saúde de referência e a satisfação das necessidades de saúde dos usuários. É possível perceber nos discursos que apesar de ser a porta de entrada principal aos serviços de saúde e pressupor uma acessibilidade maior, por ter como principal característica o trabalho desenvolvido no território, esse local de saúde nem sempre consegue oferecer o acesso a todos os usuários que o procuram. Diante desses desafios, algumas estratégias têm sido utilizadas em algumas cidades do país para a ampliação e garantia do acolhimento nas unidades, como o "acesso avançado", cujo objetivo principal seria o atendimento no mesmo dia e a continuidade no cuidado, com ampliação da agenda para a demanda imediata (Vidal, 2013).

Em outras respostas, surgiram queixas relacionadas ao acolhimento nessas unidades e ao tempo de espera para um atendimento, conforme os relatos dos entrevistados:

O posto? Eles estão em reforma, está uma bagunça lá. Não atende, não tá atendendo ... . Eu não confio porque eles são muito grossos e eu não gosto de lá. Eu não falo isso porque eu tenho um problema psicológico, mas é porque não sou só eu que reclamo, é todo mundo. (T. Souza).

Faz tempo que eu não vou no posto de saúde, nem as receitas dos meus remédios eu estou buscando ... É porque você sabe, posto de saúde, se você for marcar tem que esperar muito tempo, quando a gente tá precisando a gente não pode esperar, a gente espera 15 dias, 10 dias, mas mais não tem condição de esperar num é? Você só espera quando num tem jeito, porque se você puder pagar você paga (E. Pereira). 
No caso dos trechos acima, as entrevistadas pertenciam a territórios de UBS que ainda funcionam segundo o modelo biomédico de assistência. De acordo com Randow et al. (2011), além dos fatores já citados, a falta de recursos humanos na APS e de direcionamento/comunicação acerca do funcionamento de fluxos na saúde para os usuários seriam alguns desafios que dificultam o andamento do PA frente à atribuição de também servir como retaguarda à Atenção Básica. Uma das consequências é que o Pronto Atendimento se torna um caminho mais fácil para alcançar suporte a suas necessidades, o que se refletiu no resultado de que aproximadamente um terço dos entrevistados o procuraram sem serem referenciados.

Do mesmo modo, durante o desenvolvimento da pesquisa, 2 usuários citaram que a procura pelo serviço se deve por falta de acesso a psicólogos em serviços de saúde de porta aberta ou ao rumor de que haveria essa disponibilidade no local:

Por causa da psicóloga (motivo que veio), eu estava ruim, bem mal chorando, aí minha mãe falou que tinha plantão de psicologia, ela foi se informar e falaram para ela me trazer aqui... (K. Martins).

Porque falaram para mim que aqui tinha. Levei... (encaminhamento para psicologia no posto), até agora não chamou, faz dois anos, por isso que eu estou falando para você, lá nem adianta mandar... (E R. Almeida).

De acordo com Böing e Crepaldi (2010), na atenção básica, a maioria dos psicólogos estão presentes nas equipes do Núcleo Ampliado de Saúde da Família e Atenção Básica (NASF-AB), porém, realizam matriciamento com grande quantidade de unidades de referência de cobertura. Outro ponto de acesso de porta aberta são os Centros de Atenção Psicossocial (CAPS), que ainda não conseguem atuar de forma territorializada como organizadores dos serviços em saúde mental, nem possuem articulação estruturada com a atenção básica, fato que obteve ressonância também no munícipio participante da pesquisa.

Já as atenções secundária e terciária, que se referem aos serviços hospitalares e ambulatoriais, possuem um espaço mais estruturado, mas menos acessível a grande parte da população, e dependem conjuntamente dos fluxos de referência e contrarreferência. Sem as linhas de cuidados que acompanham os usuários de forma longitudinal pela rede, ocorrem lacunas que dificultam a corresponsabilidade entre os serviços e a assistência compatível com a complexidade dos casos passíveis de receberem ações intersetoriais (Böing \& Crepaldi, 2010).

É necessário ressaltar que, em muitos atendimentos realizados, o que se ofereceu foi uma escuta qualificada, psicoeducação, orientações sobre outros serviços disponíveis na cidade e principalmente o acolhimento. A maioria de tais atribuições não são restritas ao profissional de psicologia e podem, de acordo com a Política Nacional de Humanização (PNH), ser praticadas em todos os níveis de atenção e serviços disponíveis (MS, 2004).

Isso possivelmente se relaciona ao despreparo dos profissionais de saúde em inserir o dispositivo da clínica ampliada em seus atendimentos, no qual se considera o processo saúde-doença e o compartilhamento com equipe e usuários das condutas e propostas de cuidado, além da percepção dos sujeitos de forma integral (MS, 2009).

De forma abrangente, Nagai (2017) dialoga sobre o quanto esse despreparo sobrecarrega os serviços de urgência, pois em muitos casos haveria possibilidade de um cuidado de baixa complexidade, o que não exclui o fato de que os serviços de alta e média complexidade também deveriam se qualificar no sentido do cuidado humanizado. Nesses cenários, são comuns o uso de terapêuticas voltadas para a técnica, a medicação e um olhar acrítico e moralista sobre os usuários.

Analogamente, os profissionais citam que a formação, voltada para a abordagem biológica, contribuiu para a insegurança e ineficácia nas condutas realizadas. Na pesquisa, prevaleceram usuários que já haviam recorrido ao serviço outras vezes no ano por motivos relacionados ao sofrimento psíquico (65\% tinham recorrido de 2 a 4 vezes ou mais), o que revela que essa recorrência ocorre por não encontrarem outros pontos da rede que consigam satisfazer suas questões e pela ausência de resolutividade dos procedimentos praticados nesses casos.

Os entrevistados expõem sobre a procura regular aolocal: "ProPA... achoque umasduasvezes, eunãolembro direito. Umas duas ou três vezes. Dor no peito, ansiedade. Ansiedade, depressão e estresse" (H. Rodrigues); e "Se eu for contar quantas vezes que eu já vim aqui... pelo mesmo motivo, éangústia a suadeira, do nada vem. Na semana, duas vezes" (J. Fernandes). 
Além disso, a relação dos usuários com o PA também foi justificada pelo vínculo originado pela equipe e características do local: "Eu venho por causa que eu me sinto segura aqui, quando eu venho, eu confio" (N. Garcia); e "Eu gosto... [de vir aqui] porque as pessoas me tratam muito bem, me atende muito bem, todos. Eu venho aqui quando eu vejo que não estou bem, eu falei para as meninas que elas me atendem muito bem..." (S. Moraes).

De acordo com a Política Nacional de Atenção Básica (PNAB) (MS, 2012), o vínculo diz respeito às relações estabelecidas entre os usuários e as equipes nas quais estejam contempladas qualidades de afeto e confiança que possibilitem um aprofundamento e uma continuidade do cuidado. Embora o PA não estabeleça o contato longitudinal com os usuários, o vínculo ocorre por ser uma população que mora próxima ao local e pode contar com a assistência em qualquer momento.

Dessa forma, ressalva-se que alguns aspectos do atendimento e a perspectiva dos usuários em relação a ele estão equivocados quanto ao conceito de vínculo segundo a PNAB, pois a continuidade e o aprofundamento do cuidado não se cumprem pelo caráter pontual e transitório do trabalho da urgência. Além dos fatores já citados anteriormente, como rapidez e acessibilidade do atendimento, que são facilitadores da vinculação com o serviço, houve respostas relacionadas ao tratamento da equipe que permitem propor que os entrevistados se consideram amparados pelo atendimento prestado no local.

\section{Tema 3: Atendimento e resolubilidade}

De acordo com a Portaria n. 342 de 02 de março de 2013, do Ministério da Saúde, as UPAS devem funcionar 24 horas por dia e acolher todos os pacientes que procurarem por seus serviços, independentemente dos sintomas, de acordo com a classificação de risco, e encaminhar os casos de maior gravidade para as unidades de tratamento das especialidades médicas condizentes com os sintomas. Além disso, preconiza que haja equipe multiprofissional capacitada para apoiar a rede de atenção básica e atendimentos de urgência como o SAMU, diminuindo e redistribuindo corretamente o grande fluxo de pacientes, para que eles não superlotem os prontos socorros de hospitais de alta complexidade (Gonçalves \& Oliveira, 2020).
Dentre os participantes do trabalho, pode-se dizer que quanto ao local de estabilização de quadros de saúde agudo ou agudizado grave, poucos usuários receberam classificação correspondente a risco de morte, o que aponta para um perfil de amostragem de população que se encaixaria mais na demanda oriunda da Atenção Básica. Todos relataram satisfação com o atendimento no PA e valorização desse local de acesso. D. Santos ilustra as expectativas e a valorização do local:

Olha... eu vou te falar uma coisa, esse PA aqui quando abriu era tudo que eu pedi pra Deus, porque isso aqui para nós foi uma benção, porque quando não tinha esse PA a gente sofria, quando acontecia alguma coisa a gente ia para as [Hospital] clínicas, chegava lá a gente não era atendido tinha que mandar para outro lugar, só se fosse caso de emergência, isso aqui caiu do céu para nós. Eu amei aqui, todas as vezes que precisar que for uma emergência eu vou vir aqui mesmo. Uma emergência, assim igual hoje...

Como pontos importantes citados sobre o atendimento recebido, os entrevistados demonstraram semelhantes percepções sobre o que consideram como cuidado, no sentido de sua resolutividade. Relatam que os dispositivos oferecidos pelo local, sobretudo diante da possibilidade serem realizados exames e procedimentos, são os responsáveis pelo cuidado e por se sentirem cuidados. Em contrapartida, mencionam também os dispositivos nomeados de "tecnologia leve" (Merhy et al., 2006), como a escuta e o acolhimento.

Merhy et al. (2006) enfatizam a influência do acolhimento nas relações e nos encontros entre os profissionais de saúde e os usuários e o denomina de "trabalho vivo", por também considerar as intervenções realizadas no campo das subjetividades. Muitos participantes julgaram que foram bem atendidos baseados numa percepção de encontro afetivo e acolhedor com os profissionais do serviço:

"Ótimo, porque ela não teve preguiça ela colocou a mão em mim, me examinou, teve curiosidade de saber o que estava acontecendo, e a saúde precisa muito de médicos assim, que tenham curiosidade de mexer com a gente..." (C. Oliveira). "Foi a importância que ela (enfermeira) deu pro 
meu caso, eu vim tentando sanar um problema, eu tenho consciência de que tem outro, mas assim, como ela também identificou eu achei que isso foi bastante importante" (P. Ferreira).

O acolhimento tornou-se um dispositivo mais difundido após o surgimento da PNH do SUS (MS, 2004), uma das diretrizes que corroboram uma atitude de compromisso, reconhecimento e aceitação do outro (MS, 2010). Na saúde pública, é utilizado por vezes como denominação da organização de funcionamento queixa-conduta ou refere-se ao acesso e garantia do atendimento, mas o acolhimento ultrapassa essas concepções, na medida em que diz respeito principalmente à garantia de direito do usuário, como cidadão, a um serviço de saúde com atenção qualificada para corresponder a suas demandas (Brehmer \& Verdi, 2010).

De modo complementar, as tecnologias leve-dura e dura dependem do contato com as tecnologias leves como coordenadoras do cuidado, pois estas direcionam o uso de recursos e equipamentos (Merhy et al., 2006). Quando utilizadas separadamente, contribuem para manter uma concepção de modelo de cuidados relatados, principalmente relacionadas ao modelo assistencial hegemônico biomédico, muitas vezes tido como a referência no subjetivo dos usuários quanto ao que seria o SUS e o acesso à "saúde", conforme demonstrado pelo participante D. Santos: "O aparelho de raio $x$ já tem não tem? Antigamente fazia exame de sangue tinha que sair fora agora faz aqui não faz? Nossa, pra mim melhorou bastante, porque eu conheço desde o começo" e por A. Silva:

Eu acho que eles atendem bem a pessoa, os médicos atendem bem dão bom medicamento e eu vou tranquila para minha casa, consigo eliminar aquela angústia aquela coisa, depois que eu tomo Diazepam aquela coisa sai assim, pressão abaixa eu me acalmo, fico tranquila, e vou embora feliz.

Um dos fatores para a procura do PA seria a rapidez ao acesso a exames e equipamentos de média complexidade, que, no nível da atenção primária, necessitam de agendamento prévio ou da regulação de vagas pelo sistema que organiza uma lista de espera (Cecilio, 1997). Assim, segundo o autor, os serviços de urgência e emergência possuem destaque considerável como uma das principais portas de entrada dos usuários ao sistema de saúde brasileiro e, por isso, necessita-se repensar possibilidades de qualificação frente às múltiplas queixas dos usuários.

Percebe-se na fala da participante D. Santos que houve investimento nos instrumentos que concernem às tecnologias leve-duras, porém, quando utilizados de forma indiscriminada contribuem para a objetificação do usuário e para o incentivo a uma postura passiva diante dos modos de consumo desse cuidado. Nesse sentido, a abordagem dos profissionais reforça ou desconstrói as crenças acerca do que seria o cuidado em saúde e, consequentemente, podem ser negociados e construídos por ambos os atores de maneira que consolide os espaços para fortalecimento da autonomia e autocuidado (Merhy \& Feuerwerker, 2016).

Já em relação à resolubilidade, que é uma questão mais direcionada à rede de saúde como um todo, foi apontada como restrita ao serviço pelo fato de muitas pessoas demonstrarem dificuldade na compreensão de "rede". Entretanto, dois participantes narraram de forma sucinta as experiências com outros locais de atendimento à saúde mental:

... daqui eu fui encaminhado para o Hospital (da outra vez). E lá o médico me passou um remédio... não lembro o nome, mas é para ajudar a dormir, porque eu não estava dormindo e me explicou que eu tinha que me manter calmo, eles me deram um encaminhamento que entreguei no posto, para o médico de cabeça que vai me dar remédio para ajudar meu emocional, o psiquiatra, mas até agora nada (L. Fonseca).

Procurei o CAPS ... A gente teve essa conversa, a mesma conversa, só foi a conversa porque naquele dia eu estava bem, só precisava desabafar. (Marcou retorno?) Marcaram, mas eu não fui, porque demora muito para marcar o psiquiatra e eu não tenho paciência para esperar (T. Souza).

Pode-se dizer que a resolubilidade à qual se referiam seria a da "eliminação" do sintoma ou da indicação de como lidar com o mesmo. Os discursos mostram que muitas vezes não há corresponsabilização do tratamento com os usuários, além destes não compreenderem a proposta de alguns serviços, tais como o CAPS, e dependerem do surgimento de 
vagas em serviços que possuem pouca oferta para uma demanda grande e crescente, principalmente no ambulatório de saúde mental, no qual funcionam os atendimentos de psiquiatria. Em suma, os tratamentos resultam-se restritos ao uso contínuo de medicação.

A ausência da concepção de rede pelos usuários é um indicativo preocupante de sua fragmentação, visto que um único ponto da rede não tem como dar conta de toda a complexidade da saúde pública. Da mesma forma, reflete as práticas que têm sido perpetuadas como tratamento nesses casos e as fragilidades no acolhimento a essa demanda nos serviços de atenção primária e de portas abertas, tais como os serviços de urgência e emergência (Dimenstein et al., 2012; Nunes et al., 2016). Quanto à apreensão dos usuários sobre a resolubilidade do PA, T. Souza expressa porque considerara o atendimento no serviço resolutivo para suas necessidades:

Eu acho que hoje o que eu estava precisando era disso, talvez. Eu vim mais porque está doendo muito o machucado, sério. É por isso que eu vim, para fazer um curativo.... Eu fui atendida super rápido, eu tive tudo aqui, o médico atendeu rápido, me aconselhou dos remédios, é igual do (cita um hospital), é um hospital bom, é ótimo vir aqui, não vejo porque reclamar.

Por considerarem a resolubilidade como o conjunto dos recursos utilizados pelo serviço para um atendimento que se aproxime o máximo possível das necessidades dos usuários, tais como a continuidade do cuidado e o vínculo entre os atores envolvidos, a percepção parcial dos usuários é de que o serviço é resolutivo (Jorge et al., 2014).

Do ponto de vista do acesso e da absorção da demanda, foi visto como um espaço democrático em que grande parte da população expõe os diversos fatores que dificultam a produção de cuidado em outros pontos da rede, o que é um reflexo das desigualdades contextuais com prejuízo à promoção de saúde. No que tange ao fator qualitativo, poderiam ser mais desenvolvidos os dispositivos de tecnologia leve que auxiliam na integralidade da assistência (Santos \& Penna, 2015).

A partir de dados colhidos por Almeida, Nascimento, Rodrigues e Schweitzer (2014), observou-se que a falta de capacitação dos profissionais e o uso do senso comum em atendimento de emergências em saúde mental na atenção pré-hospitalar, distanciam a assistência prestada do cuidado esperado pelos usuários do serviço. $\mathrm{O}$ bom atendimento e a excelência no cuidado dependem diretamente do treinamento e investimento dispensado às equipes de atendimento (Braga, 2019). Observa-se também a dificuldade decorrente da falta de funcionários para atender a demanda de usuários recebidos pelos serviços, que obstaculiza o atendimento de qualidade, a atenção e os cuidados necessários (Novack, Silva, Dornelles, \& Amestoy, 2017).

Grandes dificuldades se devem aos impasses na comunicação entre os diversos níveis de saúde; assim, Hermida, Nascimento, Echevarría-Guanilo, Andrade e Ortiga (2019) defendem a referência e a contrarreferência como pontos-chave no bom atendimento aos usuários do SUS, porém, também destacam as deficiências da Atenção Básica e dos serviços especializados, em que a falta de pessoal e a demora no agendamento de atendimento prejudicam o fluxo (Hermida et al., 2019).

Metade dos entrevistados não necessitou de referenciamento, pois já realizavam acompanhamento em algum lugar. Dos encaminhados, quatro foram orientados a procurar unidade de saúde de referência para a continuidade e tratamento. Houve um caso mais grave, no qual o médico não identificou demanda para o encaminhamento de referência de maior complexidade, mas que ocorreu após diálogo com a psicologia. Os demais foram encaminhados para locais de apoio de cunho social.

Cecilio (1997, p. 477) aborda o modelo assistencial prestado na intersetorialidade dos serviços de saúde e formas de articulação, além de questionar a ampliação das portas de entradas, e pondera que “... o que importa mais é a garantia de acesso ao serviço adequado, à tecnologia adequada, no momento apropriado e como responsabilidade intransferível do sistema de saúde". De forma reflexiva, pensando nas diretrizes do funcionamento do local, o acolhimento poderia abranger tais encaminhamentos, oferecendo a essa população informações voltadas a um olhar mais integral quanto ao autocuidado. $\mathrm{O}$ autor ainda cita o aproveitamento desses "vínculos provisórios" como o início de um cuidado longitudinal e que serve como conscientização ao usuário de que o acesso é, de fato, possível e proporciona seu usufruto do direito à saúde. 


\section{Considerações finais}

Frente aos aspectos analisados, notou-se que os serviços de pronto atendimento às urgências e emergências $24 \mathrm{~h}$ compõem um cenário relevante, principalmente por estarem situados na atenção secundária e terem como um dos objetivos centrais a articulação e o direcionamento aos demais pontos da atenção à saúde. Para tanto, a identificação por parte dos profissionais, por meio das conexões que eles realizam cotidianamente, precisa receber maior investimento, principalmente em relação às demandas mais complexas que envolvem a dimensão psicossocial.

Os dispositivos reconhecidos como potentes nesse processo foram o vínculo, ainda que de caráter transitório, e o acesso, fatores determinantes para a procura pelo serviço dos usuários entrevistados. Porém, o acolhimento, que possui relação direta com a percepção de resolubilidade, apesar de ter sido bem avaliado pelos participantes, pode ser mais desenvolvido, no sentido de qualificação da escuta, clínica ampliada e abordagem integral nos cuidados disponibilizados.

Assim, nos casos mais graves e críticos, seria viável uma qualificação da equipe quanto à conduta de referenciamento e à identificação do risco, de modo que estejam alinhadas com os critérios de urgência em saúde mental. Para tanto, o estabelecimento de um fluxo mais estruturado, em conjunto com os demais serviços da RAPS, contribuiria sobretudo com a demanda de usuários em processo de crise. No que tange às queixas de menor complexidade, de característica persistente ou que envolvam recursos de seguimento, a articulação com a atenção básica nas situações de procura mais recorrente poderia reforçar a linha de cuidado mais integral.

Dessa forma, obteve-se como indicadores: a dificuldade de acesso aos serviços oferecidos no município para a saúde mental; o despreparo na atenção básica para lidar com o sofrimento psíquico e incorporar em suas práticas cotidianas a promoção de saúde nesse aspecto; a necessidade de capacitar e aumentar o conhecimento dos profissionais no setor de urgência e emergência quanto ao cuidado integral e humanizado com esses usuários, a fim principalmente de desnaturalizar os estigmas associados a essa população; e o fluxo bem definido relativo à linha de cuidado em saúde mental. Esses resultados apontam para uma construção diária de aproximações entre os pontos de atenção e áreas multiprofissionais.

Quanto aos participantes, verificou-se que as queixas mais frequentes estão relacionadas aos sintomas gerais, que podem ser considerados de base somática. Envolvem fatores multideterminantes, com significativa influência de problemas econômicos e afetivo-relacionais e prejuízos considerados graves, que incluem agravos na saúde ou surgimento de doenças crônicas não transmissíveis, devido ao comprometimento da funcionalidade e qualidade de vida.

Ressalta-se a importância de realização de pesquisas que contribuam para a expressão dos usuários sobre a percepção quanto à assistência na Saúde Pública, principalmente por serem o foco essencial ao se pensar em práticas de cuidado e atenção na saúde, na medida em que essas pesquisas podem constituir um importante meio de promover estratégias que se aproximem das necessidades reais dos usuários.

\section{Referências}

Almeida, A. B., Nascimento, E. R. P., Rodrigues, J., \& Schweitzer, G. (2014). Intervenção nas situações de crise psíquica: dificuldades e sugestões de uma equipe de atenção pré-hospitalar. Revista brasileira de enfermagem, 67(5), 708-714. https://doi.org/10.1590/0034-7167.2014670506

Almeida, F. M. (2005). Ser clínico como educador: uma leitura fenomenológica existencial de algumas temáticas na prática de profissionais de saúde e educação [Tese de doutorado, Instituto de Psicologia, Universidade de São Paulo. https://www.teses.usp.br/teses/disponiveis/47/47131/tde-08082007-180214/pt-br.php

Baratieri,T., Almeida, K.P., Lentsck, M.H.,\&Natal, S. (2017).Percepções de usuários atendidos em um ProntoAtendimento: olhar sobre a Atenção Primária à Saúde. Espaço para a Saúde, 18(1), 54-63. https://pdfs.semanticscholar.org/ ba5a/3236b5999e00d92b48af666ab8d02eea99el.pdf?a=2.127295118.287288868.1598109537-733415226.1597491971

Bardin, L. (2011). Análise de conteúdo (4a ed.). Edições 70.

Barreto, M. L. (2017). Desigualdades em Saúde: uma perspectiva global. Ciência e saúde coletiva, 22(7), 2097-2108. https://doi.org/10.1590/1413-81232017227.02742017 
Böing, E., \& Crepaldi, M. A. (2010). O psicólogo na atenção básica: uma incursão pelas políticas públicas de saúde brasileiras. Psicologia: Ciência e Profissão, 30(3), 634-649. https://doi.org/10.1590/ S1414-98932010000300014

Braga, M. D. X. (2019). Principais dificuldades do atendimento pré-hospitalar descritas pela produção cientifica nacional. Revista Eletrônica Acervo Saúde, 22. https://doi.org/10.25248/reas.e703.2019

Brehmer, L. C. F., \& Verdi, M. (2010). Acolhimento na Atenção Básica: reflexões éticas sobre a Atenção à Saúde dos usuários. Ciência \& Saúde Coletiva, 15(3), 3569-3578. http://www.scielo.br/pdf/csc/v15s3/v15s3a32.pdf

Brito, A. A. C.; Bonfada, D., \& Guimarães, J. (2015). Onde a reforma ainda não chegou: ecos da assistência às urgências psiquiátricas. Physis: Revista de Saúde Coletiva, 25(4), 1293-1312. https://doi.org/10.1590/ S0103-73312015000400013

Buss, P. M., \& Pellegrini, A. (2007). A saúde e seus determinantes sociais. PHYSIS: Revista de Saúde Coletiva, 17(1), 77-93. https://doi.org/10.1590/S0103-73312007000100006

Cecilio, L. C. O. (1997). Modelos tecno-assistenciais em saúde: da pirâmide ao círculo, uma possibilidade a ser explorada. Cadernos de Saúde Pública, 13(3), 469-478. https:// doi.org/10.1590/S0102-311X1997000300022

Dimenstein, M., Amorim, A. K. A., Leite, J., Siqueira, K., Gruska, V., Vieira, C., Brito, C., Medeiros, I., \& Bezerril, M. C. (2012). O atendimento da crise nos diversos componentes da rede de atenção psicossocial em Natal/RN. Polis e Psique, 2, 95-127. https://doi.org/10.22456/2238-152X.40323

Fertonani, H. P., Pires, D. E. P., Biff, D., \& Scherer, M. D. A. (2015). Modelo assistencial em saúde: conceitos e desafios para a atenção básica brasileira. Ciência \& Saúde Coletiva, 20(6), 1869-1878. https://doi.org/ $10.1590 / 1413-81232015206.13272014$

Fortes, S. L. C. L., Tófoli, L. F. F., \& Baptista, C. M. A. (2010). Somatização hoje. In J. Mello Filho \& M. Burd, Psicossomática hoje (2a ed., pp. 546-562). Artmed.

França, I. G. (2005). Reflexões acerca da implantação e funcionamento de um plantão de emergência em saúde mental. Psicologia: Ciência e Profissão, 25(1), 146-163. https://doi.org/10.1590/S1414-98932005000100012

Giglio-Jacquemot, A. (2005). Urgências e emergências em saúde: perspectivas de profissionais e usuários. Editora Fiocruz. https://books.google.com.br/books/about/Urg\%C3\%AAncias_e_emerg\%C3\%Ancias_em_ sa\%C3\%BAde.html?id=jhX0AgAAQBAJ\&printsec=frontcover\&source=kpread_button\&redir_esc=y\#v=onepage\&q\&f=false

Gonçalves, D. M., \& Kapczinski, F. (2008). Prevalência de transtornos mentais em indivíduos de uma unidade de referência para Programa Saúde da Família em Santa Cruz do Sul, Rio Grande do Sul, Brasil. Cadernos de Saúde Pública, 24(9), 2043-2053. https://doi.org/10.1590/S0102-311X2008000900010

Gonçalves, J. R. \& Oliveira, C. C. (2020). Estudo da politica pública sobre as unidades de pronto atendimento-(UPAS) [Trabalho apresentado]. Anais do Congresso de Políticas Públicas e Desenvolvimento Social da Faculdade Processus (pp. 17-22), evento on-line. http://periodicos.processus.com.br/index.php/acppds/article/ view/181/181

Hermida, P. M. V., Nascimento, E. R. P., Echevarría-Guanilo, M. E., Andrade, S. R., \& Ortiga, Â., M. B. (2019). Contrarreferência em Unidade de Pronto Atendimento: discurso do sujeito coletivo. Revista Brasileira de Enfermagem, 72(suppl 1), 143-150, 2019. https:// doi.org/10.1590/0034-7167-2018-0023

Jardim, K. F. S. B. (2014). Habitando o paradoxo: atenção à pessoa em crise no campo da saúde mental [Tese de doutorado, Escola Nacional de Saúde Pública Sergio Arouca]. https://www.arca.fiocruz.br/bitstream/icict/13139/1/ ve_Katita_Figueir\%c3\%aado_ENSP_2014

Jardim, K., \& Dimenstein, M. (2007). Risco e crise: pensando os pilares da urgência psiquiátrica. Psicologia em Revista, 13(1), 169-190. http://pepsic.bvsalud.org/pdf/per/v13n1/v13nla1l.pdf

Jorge, M. S. B., Vasconcelos, M. G. F., Castro Junior, E. F., Barreto, L. A., Rosa, L. R. S., \& Lima, L. L. (2014). Resolubilidade do cuidado em saúde mental na Estratégia Saúde da Família: representação social de profissionais e usuários. Revista da Escola de Enfermagem da USP, 48(6), 1062-1068. https://doi.org/10.1590/S0080-623420140000700014

Lei n. 10.216. (2011, 6 de abril). Dispõe sobre a proteção e os direitos das pessoas portadoras de transtornos mentais e redireciona o modelo assistencial em saúde mental. http://www.planalto.gov.br/ccivil_03/leis/LEIS_2001/ L10216.htm 
Macêdo, L. F., Pimenta Filho, A, J. A., Sotelo, M. I., Belaga, G., \& Santimaría, L. (2010). Análisis de la demanda e intervenciones en la urgencia em salud mental. Psicologia em Revista, 16(1), 1-16. https://doi.org/10.5752/P.1678-9563.2010v16n1pl

Merhy, E. E., Chakkour, M., Stéfano, E., Stéfano, M. E., Santos, C. M., \& Rodrigues, R. A. (2006). Em busca de ferramentas analisadoras das tecnologias em saúde: a informação e o dia a dia de um serviço, interrogando e gerindo trabalho em saúde. In E. E. Merhy \& R. Onocko (Orgs.), Agir em saúde um desafio para o público. (2a ed., pp. 113-150). Hucitec.

Merhy, E. E., \& Feuerwerker, L. C. M. (2016). Novo olhar sobre as tecnologias de saúde: uma necessidade contemporânea. In E. E. Merhy, R. S. Baduy, C. T. Seixas, D. E. S. Almeida \& H. Slomp Júnior (Orgs.), Políticas e Cuidados em Saúde: Livro 1. Avaliação compartilhada do cuidado em saúde: surpreendendo o instituído nas redes (pp. 59-72). Hexis.

Minayo, M. C. S. (2013). O desafio do conhecimento: pesquisa qualitativa em saúde (13a ed.). Hucitec.

Ministério da Saúde. (2004). HumanizaSUS: Política Nacional de Humanização: a humanização como eixo norteador das práticas de atenção e gestão em todas as instâncias do SUS. http://bvsms.saude.gov.br/bvs/publicacoes/ humanizasus_2004.pdf

Ministério da Saúde. (2009). Clínica ampliada e compartilhada. https://bvsms.saude.gov.br/bvs/publicacoes/clinica_ampliada_compartilhada.pdf

Ministério da Saúde. (2010). Acolhimento nas práticas de produção de saúde. http://bvsms.saude.gov.br/bvs/ publicacoes/acolhimento_praticas_producao_saude.pdf

Ministério da Saúde. (2012). Política Nacional de Atenção Básica. http://189.28.128.100/dab/docs/publicacoes/ geral/pnab.pdf

Ministério da Saúde. (2013). Saúde Mental. http://bvsms.saude.gov.br/bvs/publicacoes/cadernos_atencao_ basica_34_saude_mental.pdf

Nações Unidas no Brasil. (2017, 23 de fevereiro). OMS registra aumento de casos de depressão em todo o mundo; no Brasil são 11,5 milhões de pessoas. Nações Unidas Brasil. https://brasil.un.org/ pt-br/75837-oms-registra-aumento-de-casos-de-depressao-em-todo-o-mundo-no-brasil-sao-115-milhoes-de

Nagai, D. K. (2017). Diretriz de integração do SAMU com os componentes APS e UPA na Rede de Urgência e Emergência: pesquisa-ação [Dissertação de mestrado, Universidade Federal do Paraná]. https://acervodigital.ufpr.br/bitstream/handle/ 1884/49138/R\%20-\%20D\%20-\%20DANIELA\%20KUROMOTO\%20NAGAI. pdf?sequence $=1 \&$ isAllowed $=\mathrm{y}$

Novack, B. C., Silva, J. R., Dornelles, C., \& Amestoy, S. C. (2017). As dificuldades vivenciadas pelos profissionais de enfermagem no atendimento pré-hospitalar. Revista Gestão \& Saúde, 8(3), p. 453-467, 2017. https://periodicos. unb.br/index.php/rgs/article/view/10319/9106

Nunes, J. M. S., Guimarães, J. M. X., \& Sampaio, J. J. C. (2016). A produção do cuidado em saúde mental: avanços e desafios à implantação do modelo de atenção psicossocial territorial. Physis: Revista de Saúde Coletiva, 26(4), 1213-1232. https://doi.org/10.1590/S0103-73312016000400008

Perrusi, A. (2015). Sofrimento psíquico, individualismo e uso de psicotrópicos: Saúde mental e individualidade contemporânea. Tempo Social, 27(1), 139-159. https://doi.org/10.1590/0103-20702015017

Pinheiro, C. V. Q., Aguiar, I. M., \& Mendes, L. C, B. (2008). O sofrimento psíquico e as novas modalidades de relação entre o normal e o patológico: uma discussão a partir da perspectiva freudiana sobre o caráter do psicopatológico. Interação em Psicologia, 12(2), 299-305. http://doi.org/10.5380/psi.v12i2.10269

Pinheiro, R. (2008). Integralidade em saúde. In I. B. Pereira \& J. C. F. Lima (Orgs.), Dicionário da educação profissional em saúde (2a ed., pp. 255-262). EPSJV. http://www.sites.epsjv.fiocruz.br/dicionario/Dicionario2.pdf

Portaria n. 10. (2017, 3 de janeiro). Redefine as diretrizes de modelo assistencial e financiamento de UPA 24h de Pronto Atendimento como Componente da Rede de Atenção às Urgências, no âmbito do Sistema Único de Saúde. http://bvsms.saude.gov.br/bvs/saudelegis/gm/2017/prt0010_03_01_2017.html

Portaria n. 342. (2013, 4 de março). Redefine as diretrizes para implantação do Componente Unidade de Pronto Atendimento (UPA 24h) em conformidade com a Política Nacional de Atenção às Urgências, e dispõe sobre incentivo financeiro de investimento para novas UPA 24h (UPA Nova) e UPA 24h ampliadas (UPA Ampliada) 
e respectivo incentivo financeiro de custeio mensal. https://bvsms.saude.gov.br/bvs/saudelegis/gm/2013/ prt0342_04_03_2013.html

Portaria n. 3.088. (2011, 23 de dezembro). Institui a Rede de Atenção Psicossocial para pessoas com sofrimento ou transtorno mental e com necessidades decorrentes do uso de crack, álcool e outras drogas, no âmbito do Sistema Único de Saúde (SUS). https://bvsms.saude.gov.br/bvs/saudelegis/gm/2011/prt3088_23_12_2011_rep.html

Randow, R. M. V., Brito, M. J. M., Silva, K. L., Andrade, A. M., Caçador, B. S., \& Siman, A. G. (2011). Articulação com atenção primária à saúde na perspectiva de gerentes de unidade de pronto-atendimento. Revista da Rede de Enfermagem do Nordeste, 12, 904-912. http://periodicos.ufc.br/rene/article/view/4370/3344

Santos, T. V. C., \& Penna, C. M. M. (2015). Acessibilidade e resolutividade dos serviços de saúde: perspectivas de usuários e profissionais. Revista Pensar Acadêmico, 12(1), 98-108. http://pensaracademico.facig.edu.br/index. $\mathrm{php} /$ pensaracademico/article/view/213

Vidal, T. B. (2013). O acesso avançado e sua relação com o número de atendimentos médicos em atenção primária à saúde [Dissertação de mestrado, Faculdade de Medicina, Universidade Federal do Rio Grande do Sul]. https:// lume.ufrgs.br/bitstream/handle/10183/87111/000910522.pdf?sequence=1\&isAllowed=y

\section{Beatriz da Silva Souza}

Psicóloga Residente do Programa de Residência Integrada Multiprofissional em Urgência da Faculdade de Medicina de Marília (Famema), Marília - SP. Brasil.

E-mail: bea_ssouza@hotmail.com

(1) https://orcid.org/0000-0002-9504-3729

\section{Danielle Abdel Massih Pio}

Doutora em Saúde Coletiva pela Faculdade de Medicina, Campus de Botucatu, da Universidade Estadual Paulista (Unesp), Botucatu - SP. Brasil. Assistente de Ensino da Faculdade de Medicina de Marília (Famema), Marília - SP. Brasil. Tutora da Residência Integrada Multiprofissional em Urgência da Faculdade de Medicina de Marília (Famema), Marília - SP. Brasil.

E-mail: danimassihpio@hotmail.com

(1) https://orcid.org/0000-0003-0738-4601

\section{Gabriela Teixeira Ribeiro de Oliveira}

Psicóloga Residente do Programa de Residência Integrada Multiprofissional em Urgência da Faculdade de Medicina de Marília (Famema), Marília - SP. Brasil.

E-mail: gtroliveira93@gmail.com

(1) https://orcid.org/0000-0002-4377-7376

Endereço para envio de correspondência:

Rua Urias Avelino de Moraes, 204, César de Almeida. CEP: 17511-830. Marília - SP. Brasil.

Recebido 26/03/2019

Aceito 30/09/2020

Received 03/26/2019

Approved 09/30/2020

Recibido 26/03/2019

Aceptado 30/09/2020 
Psicologia: Ciência e Profissão 2021 v. 41, e221805, 1-16.

Como citar: Souza, B. S., Pio, D. A. M., \& Oliveira, G. T. R. (2021). Perspectivas de Usuários em Sofrimento Psíquico Sobre um Serviço de Pronto Atendimento. Psicologia: Ciência e Profissão, 41, 1-16. https://doi.org/10.1590/ 1982-3703003221805

How to cite: Souza, B. S., Pio, D. A. M., \& Oliveira, G. T. R. (2021). The Perspectives of Users in Psychic Suffering About an Emergency Service. Psicologia: Ciência e Profissão, 41,1-16. https://doi.org/10.1590/ 1982-3703003221805

Cómo citar: Souza, B. S., Pio, D. A. M., \& Oliveira, G. T. R. (2021). Perspectivas de Usuarios en Sufrimiento Psíquico Sobre un Servicio de Urgencia. Psicologia: Ciência e Profissão, 41, 1-16. https://doi.org/10.1590/ 1982-37030032218053703003221805 